\title{
Application of Different Modelling Methods to Arbitrate Various Hydrological Attributes Using CMORPH and TRMM Satellite Data in Upper Omo-Gibe Basin of Ethiopia
}

\author{
Abera Ermias Koshuma ${ }^{(D},{ }^{1}$ Yegelilaw Eyesus Debebe ${ }^{(D)},{ }^{1}$ Defaru Katise Dasho ${ }^{(D)}{ }^{2}$ \\ and Tarun Kumar Lohani $\mathbb{D}^{1}$ \\ ${ }^{1}$ Arba Minch Water Technology Institute, Arba Minch University, P.O. Box: 21, Arba Minch, Ethiopia \\ ${ }^{2}$ Arba Minch Institute of Technology, Arba Minch University, P.O. Box: 21, Arba Minch, Ethiopia \\ Correspondence should be addressed to Tarun Kumar Lohani; tklohani@gmail.com
}

Received 7 September 2021; Revised 8 November 2021; Accepted 20 November 2021; Published 7 December 2021

Academic Editor: Chao Hu

Copyright ( $\odot 2021$ Abera Ermias Koshuma et al. This is an open access article distributed under the Creative Commons Attribution License, which permits unrestricted use, distribution, and reproduction in any medium, provided the original work is properly cited.

\begin{abstract}
Rainfall is a basic input parameter for hydrological modelling that exerts a great influence on the dependability of hydrological simulations. Limited availability of accurate and reliable precipitation data in Abelti watershed of Omo Gibe basin of Ethiopia coerces to use satellite rainfall data to design watershed management practices. The primary objective of this research is to find a better output by comparing and evaluating Climate Prediction Centre Morphing techniques (CMORPH) and Tropical Rainfall Measuring Mission (TRMM). Satellite precipitation products (SPPs) and inputs were incorporated to simulate stream flow. Sensitivity and uncertainty analysis, calibration, and validation of the model were conducted using Soil and Water Assessment Tool (SWAT), Calibration and Uncertainty Program 2012 (SWAT-CUP-2012), particularly the Sequential/Uncertainty Fitting (SUFI-2) algorithm for all rainfall inputs independently. The calibration and validation period was taken as 2003-2010 and 2011-2018, respectively. On the basis of the modelling results of SWAT and uncertainty analysis, TRRM relatively performed well than that of CMORPH. The result illustrated that the SWAT model thoroughly predicted the catchment runoff simulation for all SPPs. However, TRMM-based simulations capture the shape of the observed stream flow hydrograph, and there was slight under and overestimation of the stream flow volume simulated SPPs followed by the reduction of model performance statistics. Biascorrected satellite rainfall-based simulations significantly improved the model performance as well as the volume of stream flow simulated. The detail study exhibited that the in situ-based simulation outperformed satellite products in terms of the objective functions in the study area.
\end{abstract}

\section{Introduction}

Data exhibited from rainfall is one of the crucial components for numerous hydrological modelling and applications where data quality yields a phenomenal influence on hydrological simulation results and accurate prediction of floods as well as assessing of water resources potential $[1,2]$. However, the evaluations of SPPs have certain restrictions in terms of the deficiency in observation, assessment way, the assortment of time windows for estimation, and rapid time for calculation. Methods for satellite SPPs have some constraints and embedded uncertainties since they do not directly measure precipitation by itself and are linked to it based on one or numerous substitute variables [3]. The basin scale forecasts of waterway runoff at diverse warming stages provide valuable evidence for changing climate adoption [4], examined fluctuations in the projected climate, and simulated runoff to get more complex changes with large uncertainty.

In many African countries, the hydrological simulation is undertaken using the conventional approach, (gauged observation data) but spatial coverage of the hydrometeorological stations is limited resulting to uneven distribution of spatiotemporal or nonexistence $[5,6]$. Ethiopia lying in 
the same continent faces similar challenges due to inadequate resources of data from limited gauging stations. To overwhelm some of the aforesaid restrictions of the conventional approach (gauged rainfall data) measurements, satellite-based estimation of rainfall gives an unconventional approach (remotely sensed rainfall products) for hydrological investigation and water resources applications. A major role for scientific hydrological applications has been considered to assess consistent rainfall estimates and its spatial and temporal distribution [7-10]. High resolution SPPs Climate Hazards Group Infrared Precipitation (CHIRPS) and TRMM Multisatellite Precipitation Analysis 3B42 Version7 (TMPA 3B42V7) for stream flow simulation at daily scale at Dabus Watershed of Abay Basin of Ethiopia displays the Hydrologic Engineering Centre-Hydrologic Modelling System (HEC-HMS) model prediction thriving in the catchment runoff for all SPPs [11].

The global satellite precipitation products contribute adequate information for water resource management in data limited region of the basin [12]. The effects of bias correction of CMORPH rainfall products on runoff simulation through the Hydrologiska Byråns Vattenbalansavdelning (HBV) model at the same catchment predicted the performance of Hydrologiska Byråns Vattenbalansavdelning (HBV) theatrically improves in the watershed when compared to the uncorrected CMORPH products [13]. The performance of SWAT model for stream flow simulation using CMORPH satellite rainfall estimates and in situ-based rainfall data for a period of six years (2003-2008) for the Gilgel Abbay catchment illustrating the SWAT model yields remarkable results for CMORPH satellite rainfall estimate-based simulations than in situ rainfall data-based simulations [14]. High resolution CMORPH satellite rainfall estimate in Gilgel Abbay watershed predicts the satellite rainfall estimate for three months using experimental in situ rainfall data networks with the accuracy of CMORPH product depending on the basin area that was poorly correlated with in situ rainfall data observations [15]. Assessment of small watersheds like Gilgel Abbay and Koga in Abbay basin of Ethiopia using the SWAT model has already been undertaken by four high resolution SPPs such as CMORPH, satellite-only product TRMM TMPA3B42RT, satellite gauge product TRMM TMPA3B42, and Precipitation Estimation from Remotely Sensed Information using Artificial Neural Networks (PERSIANN) [16]. Consistent and modest simulation has been illustrated by 3B42RT and CMORPH products, while 3B42 and (PERSIANN) simulations have showed inconsistent performance with poor skills, but 3B42RT and CMORPH products underestimate the large flood peaks concluding that 3B42RT executes better than $3 \mathrm{~B} 42$ products. This is due to the algorithm used to incorporate rain gauge information with the goal of improving the accuracy of SPPs. However, CMORPH and 3B42 satellite rainfall products demonstrate consistent and modest skills in their simulation in terms of volume and statistical performance. Many studies are undertaken in various watersheds of Ethiopia, but no such remarkable studies have been commenced in Omo Gibe river basin.

The purpose of this research is to compare and evaluate TRMM, TMPA3B42v7, and CMORPH satellite rainfall estimates to assess the competency to identify and capture the magnitude of rainfall patterns, to evaluate the skill of satellite precipitation products as an input for hydrological modeling, and to assess the predictability of SWAT model through SPPs and gauged rainfall.

\section{Materials and Methods}

2.1. Study Area. Abelti watershed is located in the upper part of Omo-Gibe Basin and has many hydrological and meteorological gauging stations compared to the lower OmoGibe Basin. The major rivers are Gilgel-Gibe, Gojeb, Gibe, Tunjo, Wabe, Walga, and Warabessa. The basin covers an area of $33,018 \mathrm{~km}^{2}$. The Abelti watershed is located $7^{\circ} \mathrm{N}$ to $9^{\circ} 30^{\prime} \mathrm{N}$ latitude and $36^{\circ} 30^{\prime} \mathrm{E}$ to $38^{\circ} 30^{\prime} \mathrm{E}$ longitude, and it is the main tributary of the Omo-Gibe basin. Gilgel Gibe River is the main river in the catchment which covers an area of $15,746.8 \mathrm{~km}^{2}$. The northern and central half of the basin lies at an altitude greater than 150 meters above the mean sea level (m.a.s.l). The maximum elevation is located between Gilgel, Gibe and Gojeb tributaries which are 3360 m.a.s.l. The headwaters of the Great-Gibe River are at an elevation of about 2200 m.a.s.l and the weather is semihumid with an average yearly rainfall of $1140 \mathrm{~mm}$ as well as the mean temperature in the watershed is $25^{\circ} \mathrm{C}$. The land is covered by crop land (67.06\%), forest and shrubs (14.60\%), urban $(11.82 \%)$, and water $(6.53 \%)$. Soils are dominantly fine texture comprising sandy loam and silt (49.5\%), clay (35\%), and loamy clay (14.5\%) (Figure 1).

2.2. Hydrometeorological Data. Meteorological data for a period of 19 years (2000-2018) from thirty-four stations with different time series (all necessary components) were assessed from National Meteorological Agency (NMA) of Ethiopia. Among these stations, only eight gauging stations based on their completed data were collected. Additionally, the daily stream flow records at the outlet of Abelti catchment (Gilgel-Gibe), stream flow gauging station from 2000 to 2018 as well as digital elevation model (DEM), LULC, and soil data were collected from Ministry of Water, Irrigation and Energy (MoWIE). All these data were used as input parameters for the hydrological model. To establish SWAT model database, the solar radiation (Rs) data were calculated using the sun shine hours $(n)$ employing Rs index with Penman Monteith method.

2.3. Satellite Precipitation Products. The main characteristics of the CMORPH and TMPA3B42v7 SPPs used were discussed and investigated for their suitability to show precipitation patterns and extremes over the Abelti watershed. These rainfall datasets were considered due to their high spatiotemporal resolution, availability of data, as well as relatively high accuracy and coverage domain.

2.3.1. CMORPH. Climate Prediction Centre's morphing technique (CMORPH) is derived from the morphing technique that uses precipitation estimates assessed from 


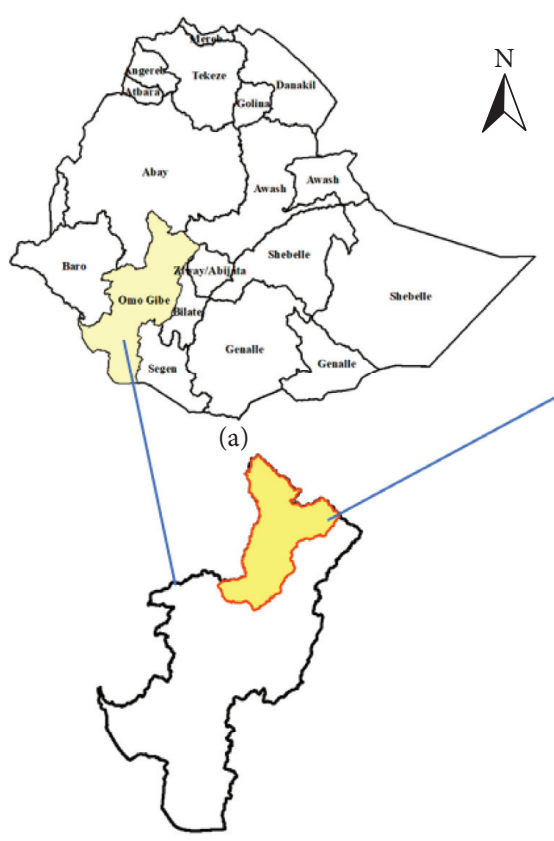

(b)

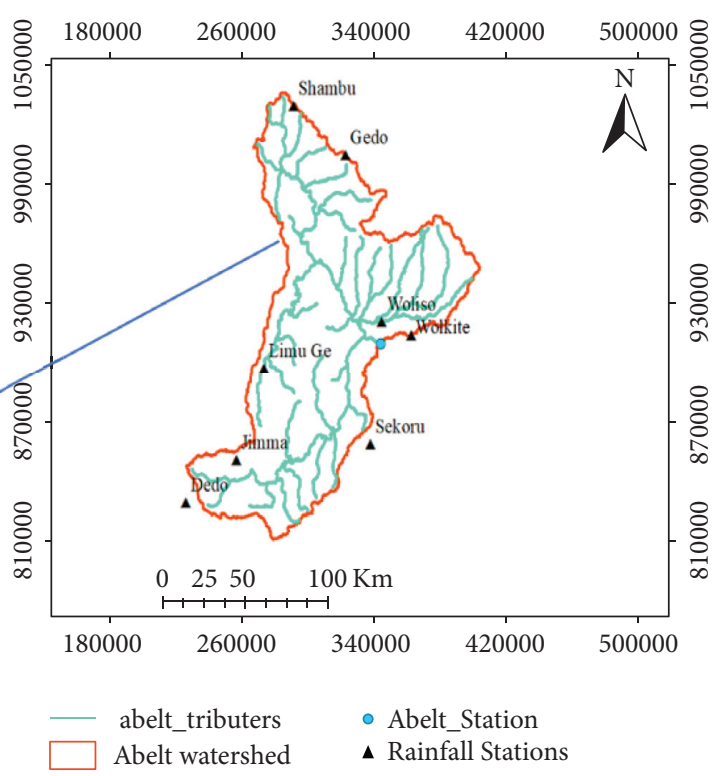

(c)

Figure 1: Location map of the study area: (a) basins of Ethiopia; (b) Omo Gibe river basin; (c) Abelt catchment.

passive microwave (MW) observations and propagates the features in space using motion vectors imitative from halfhourly geostationary satellite infrared data [17]. This is one of the satellite precipitation products available at different temporal and spatial scales. CMORPH version 0x products (corresponding to the eight-time period per day, i.e., UTC $00,03,06,09,12,15,18$, and 21) rainfall data from 2000 to 2018 were extracted and aggregated to daily based (Table 1 ).

2.3.2. TRMM TMPA3B42v7. This data set is the output from Tropical Rainfall Measuring Mission (TRMM) Multi Satellite Precipitation Analysis (TMPA) post-real-time research version, product $3 \mathrm{~B} 42 \mathrm{v} 7$ algorithm, which provides precipitation estimates in the tropical and subtropical (TRMM) regions. The algorithm uses microwave (MW) data to calibrate the infrared (IR) estimates containing MW derived rainfall when and where MW data are available and the calibrated IR estimates where MW data are not available [18]. The gauge adjusted post-real-time products are considered (Table 1).

2.4. Methods. A comparison of TMPA3B42v7 and CMORPH data were conducted using statistical indices coefficient of variance (CV), standard deviation (SD), and mean $(\bar{X})$ from 2000 to 2018 . The in situ data was interpolated using Thiessen polygon method to compute longterm area rainfall and high resolution SPPs as well as the gauged rainfall data was used as an input for stream flow simulation of the SWAT model at daily and monthly time scale in the watershed. To fit the observed flow through model calibration, model parameter was used. The model calibration and validation period ranges from 2003 to 2010 and from 2011 to 2018 for CMORPH, TMPA3B42v7, and in situ data, respectively. The performance of SWAT model was evaluated by using the Nash-Sutcliffe coefficient (NSE), percent bias (PBIAS), and coefficient of determination $\left(R^{2}\right)$.

2.4.1. Statistical Analysis Methods. The coefficient of variance $(\mathrm{CV})$, standard deviation $(\mathrm{SD})$, and mean $(\bar{X})$ were applied to measure the performance of satellite-driven precipitation products with the corresponding in situ data:

$$
\begin{aligned}
\mathrm{CV} & =\frac{\mathrm{SD}}{\bar{X}} \\
\mathrm{SD} & =\sqrt{\sum_{i=1}^{n} \frac{1}{N}\left(X_{i}-\bar{X}\right)^{2}}, \\
\bar{X} & =\frac{1}{N} \sum_{i=1}^{n} x_{i} .
\end{aligned}
$$

2.4.2. SWAT Model. As a physically based model, Soil Water Assessment Tools (SWAT) uses a hydrological response unit (HRUs) to describe the spatial heterogeneity of LU, soil types, and slopes within a watershed $[19,20]$. The model assumes that there is no interaction between HRUs in a single sub-basin. According to the water balance cycle, the HRU hydrologic process is initially calculated and added to obtain the total hydrologic process of the subbasin [21]. Precipitation, surface runoff, evapotranspiration, infiltration, lateral and base flow, and percolation of shallow and deep aquifers are part of the water balance equation 
TABLE 1: Satellite precipitation products of the study area.

\begin{tabular}{lcccc}
\hline Product type & Temporal coverage & Spatial coverage & Temporal resolution & Spatial resolution \\
\hline TMPA 3B43 v7 & 1998 -present & $50^{\circ} \mathrm{S}-50^{\circ} \mathrm{N}$ & Daily & $0.25^{\circ} \times 0.25^{\circ}(\sim 27 \mathrm{~km})$ \\
CMORPH & $1998-$ present & $60^{\circ} \mathrm{S}-60^{\circ} \mathrm{N}$ & Daily/month & $0.25^{\circ} \times 0.25^{\circ}(\sim 27 \mathrm{~km})$ \\
\hline
\end{tabular}

$$
\mathrm{SW} t=\mathrm{SWo}+\sum_{i=1}^{t} \mid[P-\text { Qsurf }-\mathrm{Ea}-\mathrm{Wseep}-\text { Qlat }- \text { Qgw }] \mid
$$

where SW $t$ is the soil's water content at the end of period $t$ $(\mathrm{mm}), \mathrm{SW}_{0}$ is the soil water content at the beginning of period $t(\mathrm{~mm})$, and $t$ is the calculation period length, $P=$ precipitation, $\quad$ Qsurf $=$ surface runoff, $\mathrm{Ea}=$ evapotranspiration, Wseep = the amount of percolation and by pass flow exiting the soil profile bottom, Qlat = lateral flow, and Qgw = base flow, including return flow from the shallow aquifer (GWQ) and flow out from the deep aquifer (GWQD) all on day $i$ in $\mathrm{mm}$.

Surface runoff/verland flows occur along a sloping surface and it is the major component of the hydrologic cycle. SWAT provides the surface runoff computation methods using the soil conservation service (SCS) curve number $(\mathrm{CN})$ method to simulate surface runoff

$$
\frac{F}{S}=\frac{\text { Qsurf }}{P-\text { Ia }}
$$

where; $S=$ retention parameter $(\mathrm{mm}), P=$ rainfall depth for the day $(\mathrm{mm}), \mathrm{Qsurf}=$ accumulated runoff or rainfall excess, and $\mathrm{Ia}=$ initial loss in $\mathrm{mm}$ (precipitation loss before surface runoff), $F=$ final loss in $\mathrm{mm}$ (precipitation loss after surface runoff).

\subsubsection{SWAT Model Calibration and Validation.} Calibration has been initiated to achieve better performance for the given set of local conditions reducing the prediction uncertainty. A split sample procedure was adopted at Gilgel-Gibe stream flow gauging station using monthly flow data from the period 2003-2010 and 2011-2018 for calibration and validation of the model, respectively. The first two years used as "warm-up" periods for initializing model state variables were omitted. For the same period, independent calibration and validation were used for CMORPH and TMPA3B42v7 precipitation products. The Sequential Uncertainty Fitting algorithm version 2 (SUFI-2) in SWAT-Calibration and Uncertainty Program (SWAT-CUP) was used to calibrate the SWAT model automatically. The model was calibrated by different iterations for 1000 times each. SWAT CUP generated a fresh set of parameter for all iterations followed by the new set used for the next iteration after considering the maximum and minimum bounds. This method was repeated again and again for each SPPs data set. The objective function to optimize the model calibration, such as Nash efficiency coefficient $\left(N_{\mathrm{SE}}\right)$, percent bias (PBIAS), and regression coefficient $\left(R^{2}\right)$, was used. According to Moriasi et al., [22], the model performance was defined and classified based on $N_{\mathrm{SE}}$.

$$
N_{\mathrm{SE}}=1-\frac{\sum\left[\left(Q_{o}\right) i-\left(Q_{s}\right) i\right]^{2}}{\sum\left[\left(Q_{o}\right) i-\left(Q_{o}\right) i\right]^{2}}
$$

The percentage bias (PBIAS) was used to evaluate the model simulation results. It ranges from 0 to $+\infty$, and the optimal value is 0 [23].

$$
\text { PBIAS }=100 * \frac{\left[\sum\left(Q_{o}\right) i-\sum\left(Q_{s}\right) i\right]}{\sum\left(Q_{o}\right) i} .
$$

The coefficient determination $\left(R^{2}\right)$ describes the proportion of the total variance in the observed data that can be explained by the model. The closer the value of $R^{2}$ to 1 , the higher is the agreement between the simulated and the measured flows

$$
R^{2}=\frac{\left[\sum\left(Q_{o}\right) i-\left(\bar{Q}_{o}\right) *\left(\left(Q_{s}\right) i-\left(\overline{Q_{s}}\right)\right)\right]^{2}}{\left[\sum\left(Q_{s}\right) i-\left(\bar{Q}_{s}\right) *\left(\left(Q_{o}\right) i-\left(\overline{Q_{o}}\right)\right)\right]^{2}}
$$

where $Q_{s}$ is simulated flow, $\overline{Q_{o}}$ is observed mean flow, $Q_{o}$ is observed flow, and $\overline{Q_{s}}$ is simulated mean flow.

\section{Results and Discussion}

3.1. Comparison of In Situ Rainfall Data with SPPs. The rainfall data used in this study were collected from gauged rainfall measurements, CMORPH and TMPA3B42v7 SPPS for a period of 19 years (2000-2018) (Figure 2). TMPA3B42v7 products performed well for the year 2000-2012 while slightly underestimated the gauged rainfall 2012-2014, whereas CMORPH products underestimate the gauged rainfall from the year 2000-2003 and overestimate the observed gauged rainfall from the year 2003-2005 and consistently overestimate from the year 2007-2018.

The mean annual rainfall of TMPA3B42v7 product was found to be $1605.7 \mathrm{~mm}$. On the other hand, the mean annual rainfall of in situ measurement was estimated as $1595.5 \mathrm{~mm}$. These results show that there is no significant difference between the gauged rainfall measurements and TMPA3B42v7 satellite product. On the contrary, CMORPH exhibited a relatively high overestimation with $1699.85 \mathrm{~mm}$ of the mean values when compared with the observed gauged rainfall (Figure 2). Based on daily mean values, Dedo (6 mm/day) station showed a broader difference between gauged and CMORPH when compared to Sekoru $(3.5 \mathrm{~mm} /$ day) and other stations. CMORPH also underestimates in Wolkite which is $3.1 \mathrm{~mm} /$ day and both Jimma and Gedo underestimate by $2.9 \mathrm{~mm} /$ day. Limugenet, Woliso, and Shambu $(2.7 \mathrm{~mm} /$ day, $2.2 \mathrm{~mm} /$ day, and $1.9 \mathrm{~mm} /$ day) underestimate the observed gauged rainfall respectively. In the case of TMPA3B42V7, the difference is much smaller than CMORPH satellite products in all stations. Jimma, Wolkite, Sekoru, and Dedo have the same mean value $(<2 \mathrm{~mm} /$ day), while the other stations like Gedo, 


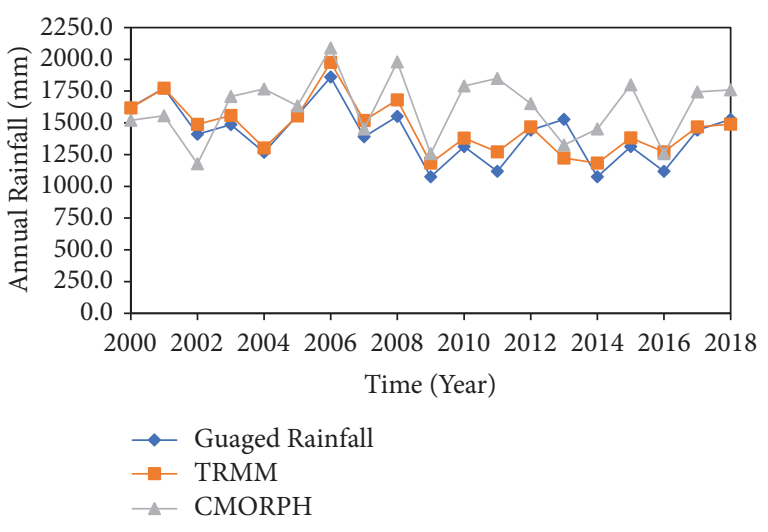

Figure 2: Mean annual rainfall of the in situ and SRPs.

Limugenet, Woliso and Shambu have a value $\leq 1 \mathrm{~mm} /$ day. The difference between gauged and SPPs displayed altitude-dependent trends, CMORPH showed higher difference in high elevation areas, whereas TRMM3B42V7 showed higher difference in low altitude areas [24]. Mean values for all groundbased stations are higher than satellite rainfall estimates and thus indicate that both the selected satellite rainfall estimates underestimate rainfall compared to in situ measurements across the Abelti watershed (Table 2).

According to the standard deviation values, only Gedo station indicated a higher value $(>3 \mathrm{~mm} /$ day $)$ for both TMPA3B42v7 and CMORPH satellite products. Dedo and Shambu, standard deviation values indicated that the CMORPH products may have higher than other stations $(<2 \mathrm{~mm} /$ day). Based on the standard deviation which measures the spread of rainfall estimates, it can be perceived that all satellite precipitation products overestimate and underestimate the gauged rainfall and follow the pattern of the mean at different spatiotemporal scales. Using CV, the degree of variation of SPPs and gauge data can be computed as the ratio of standard deviation to mean. Less variation is indicated in satellite rainfall estimates than gauge rainfall, which indicates less temporal variability of SPPs than gauge rainfall. Generally, TMPA3B42v7 SPPs exhibited excellent performance in terms of capturing the volume of annual rainfall than the CMORPH SPPs.

\subsection{SWAT Model Results for In Situ Measurements}

3.2.1. Sensitivity Analysis. The ranks of the parameters were assigned based on $t$-state and $p$ value which are derived from the sensitivity analysis by SUFI2. The $p$ value signposts the significance of sensitivity as well as $t$-stat provides the measure of the parameter sensitivity [25]. The greater the absolute value of t-stat, the sensitivity of the parameters is very high. Out of sixteen parameters used in the analysis, eleven were sensitive to stream flow based on the measure their dominant contribution value ( $T$-stat) relatively high absolute and $p$ value approaches to zero through repeatedly analysis. Curve, number (CN2) was the highest sensitive parameter to stream flow. Since it is a function of land use, soil permeability, and antecedent soil conditions, changes in land use commensurate with a relative change in stream flow has a significant influence on the overland flow. Higher the $\mathrm{CN} 2$ values results in increasing of runoff and simultaneously decreasing base flow, the daily time for recharge of the aquifer (GW-Delay, days) and threshold depth of water in the shallow aquifer required for return flow to occur (GWQMN, $\mathrm{mm} \mathrm{H}_{2} \mathrm{O}$ ). The base flow recession constant (Alfa-Bf, day) reflects the response of the subterranean flow to the change in recharge. Therefore, calibration of this parameter enables better fitting of the hydrograph. Other sensitive parameters included in the sensitive analysis were statistically irrelevant $(p>0.005)$ for stream flow simulation (Table 3).

3.2.2. Calibration and Validation. The model performance was evaluated as the initial simulation through model default parameter values before the calibration. There is dissimilarity between the observed and simulated of the stream flow hydrograph when compared to the simulation of the model with default parameter values. Consequently, the default model flow simulation result has been adjusted until the model result shows an acceptable agreement with the observed flow data. Based on the degree of sensitivity value ( $T$ stat), parameter with higher absolute value is more sensitive and corresponding significance of the sensitivity ( $p$ value) neighbouring to zero has more significance was selected for standardisation and verification procedure (Table 3).

The criteria set to evaluate the performance of the model set up rated as "good" for the study area by considering the performance statics for calibration and validation. Based on the model performance statistics, the SWAT model captures significantly the observed stream flow with model calibration and validation results of gauged rainfall input (Table 4).

Monthly simulated to monthly observed stream flow displayed a good relationship between the data set within an $E_{\mathrm{NS}}$ of 0.89 and $R^{2}$ of 0.9 and $E_{\mathrm{NS}}$ of 0.68 and $R^{2}$ of 0.76 for the calibration and validation period (Figure 3 ). The model captured the monthly time series of stream flow as well as the trends during the calibration and validation periods.

Even though the observed and simulated discharges matched for the calibration and validation period, there were underestimations of the observed discharge with percent bias (PBIAS) of $8.2 \%$ and $16.5 \%$ for the calibration and validation period, respectively. The mean monthly observed and simulated flow during the period of calibration (2003-2010) were estimated $333.06 \mathrm{~m}^{3} / \mathrm{s}$ and $299.97 \mathrm{~m}^{3} / \mathrm{s}$, respectively, which represent an underestimation of the observed stream flow by $8.2 \%$. Similarly, for the validation period (2011-2018), the mean observed and simulated monthly flow were estimated $310.18 \mathrm{~m}^{3} / \mathrm{s}$ and $402.98 \mathrm{~m}^{3} / \mathrm{s}$ respectively and also underestimated the simulated by $16.5 \%$. The simulated mean monthly flow achieved relatively differs from other studies in the watershed. This alteration is due to the spatiotemporal changes in rainfall, watershed area, and length of the study period.

3.2.3. Uncertainty Analysis. In SUFI- 2 results, the $p$-factor is 0.81 and $r$-factor is 0.68 for calibration, whereas for validation 0.68 and 0.76, respectively, at the Great Gibe gauging station. It implies $81 \%$ and $68 \%$ of the observed data of the calibration and validation were bracketed by 95 percent prediction uncertainty (95PPU) with a better estimation 
TABLE 2: Daily statistical indices of in situ and SPPs of different gauging stations.

\begin{tabular}{|c|c|c|c|c|c|c|c|c|c|}
\hline Gauge stations & Rainfall type & Mean (mm) & Std. deviation & $\mathrm{CV}$ & Stations & Rainfall type & Mean $(\mathrm{mm})$ & Std. deviation & $\mathrm{CV}$ \\
\hline \multirow{3}{*}{ Shambu } & In situ & 10.3 & 10.7 & 1.0 & \multirow{3}{*}{ Dedo } & In situ & 12.1 & 10.6 & 0.9 \\
\hline & TRMM3B42V7 & 9.3 & 9.7 & 0.9 & & TRMM3B42V7 & 10.9 & 9.8 & 1.0 \\
\hline & CMORPH & 8.4 & 8.5 & 1.0 & & CMORPH & 6.1 & 7.8 & 1.3 \\
\hline \multirow{3}{*}{ Gedo } & In situ & 11.5 & 12.3 & 1.1 & \multirow{3}{*}{ Sekoru } & In situ & 9.4 & 7.4 & 0.8 \\
\hline & TRMM3B42V7 & 10.7 & 8.9 & 0.9 & & TRMM3B42V7 & 7.8 & 7.0 & 0.9 \\
\hline & CMORPH & 8.6 & 8.5 & 1.0 & & CMORPH & 5.9 & 6.7 & 1.1 \\
\hline \multirow{3}{*}{ Jimma } & In situ & 11.8 & 10.2 & 0.9 & \multirow{3}{*}{ Limu Ge } & In situ & 10.2 & 9.5 & 0.9 \\
\hline & TRMM3B42V7 & 9.9 & 10.3 & 1.0 & & TRMM3B42V7 & 9.5 & 10.5 & 1.2 \\
\hline & CMORPH & 8.9 & 9.0 & 1.0 & & CMORPH & 7.5 & 9.9 & 1.3 \\
\hline \multirow{3}{*}{ Wolkite } & In situ & 11.8 & 11.3 & 1.0 & \multirow{3}{*}{ Woliso } & In situ & 9.4 & 7.7 & 0.8 \\
\hline & TRMM3B42V7 & 10.5 & 10.0 & 1.0 & & TRMM3B42V7 & 8.6 & 8.8 & 1.0 \\
\hline & CMORPH & 8.8 & 9.5 & 1.1 & & CMORPH & 7.2 & 8.4 & 1.2 \\
\hline
\end{tabular}

TABLE 3: Selected model parameters for calibration of in-situ rainfall.

\begin{tabular}{|c|c|c|c|c|c|c|}
\hline Parameter name & $T$-stat & $p$ value & Rank & Parameter range & Fitted value & Sensitivity \\
\hline $\mathrm{CN}_{2}$ & 22.22 & 0.001 & 1 & {$[-0.2-0.2]$} & -0.02 & Highly sensitive \\
\hline GW-DELAY & 8.37 & 0.001 & 2 & {$[30-450]$} & 47.5 & Highly sensitive \\
\hline GWQMN & 5.85 & 0.001 & 3 & [0-5000] & 141.67 & Highly sensitive \\
\hline SOL-AWC & 5.71 & 0.001 & 4 & {$[-0.25-0.25]$} & 0.13 & Highly sensitive \\
\hline ALPHA-BF & 3.49 & 0.001 & 5 & {$[0-1]$} & 0.12 & Highly sensitive \\
\hline REVAPMN & 2.16 & 0.03 & 6 & {$[0-500]$} & 110.83 & Moderate \\
\hline $\mathrm{CH}-\mathrm{K} 2$ & 1.56 & 0.118 & 7 & {$[0.01-150]$} & 95.75 & Moderate \\
\hline CANMAX & 1.23 & 0.217 & 8 & [0-10] & 7.58 & Moderate \\
\hline SOL-Z & 0.967 & 0.333 & 9 & {$[-0.25-0.25]$} & -0.18 & Low \\
\hline ESCO & 0.95 & 0.341 & 10 & [0-1] & 0.17 & Low \\
\hline EPCO & 0.333 & 0.743 & 11 & {$[0-1]$} & 0.46 & Low \\
\hline
\end{tabular}

TABLE 4: Monthly calibration and validation for model performance.

\begin{tabular}{|c|c|c|c|c|c|}
\hline \multirow[b]{2}{*}{ Model stage } & \multicolumn{5}{|c|}{$\begin{array}{l}\text { Performance statistics with in situ } \\
\text { rainfall data }\end{array}$} \\
\hline & $E_{\mathrm{NS}}$ & $R^{2}$ & PBIAS (\%) & $\begin{array}{c}p \\
\text { factor }\end{array}$ & $r$-factor \\
\hline Calibration (2003-2010) & 0.89 & 0.9 & -8.2 & 0.71 & 0.68 \\
\hline Validation (2011-2018) & 0.68 & 0.76 & 16.5 & 0.68 & 0.76 \\
\hline
\end{tabular}

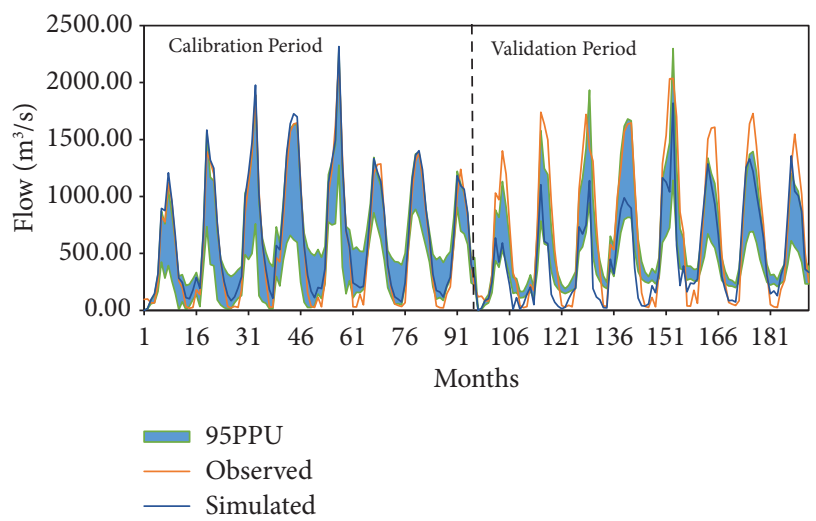

Figure 3: Monthly calibration and validation results of the observed and in situ rainfall-based simulation flow. result $(r$-factor $<1)$ for both the cases. This result displayed that the SWAT model has a tolerable/low level of uncertainty for the estimation of flow. Most of the observed peak values were depicted from June to November 2003 and from July to December 2004, May to October 2006 during the calibration period, while for the validation period (Figure 3) from May to December 2009 and 2010 were found to be above the 95PPU band. This is due to the reason that the SWAT model is not capable to simulate extreme events. However, it is known that for a parameter, model structure, and data input can also cause uncertainty in model simulation [26].

3.3. SWAT Modelling Results for Satellite Rainfall Estimates. The purposes of this study were to evaluate the performance of SWAT models with SPPs such as TMPA3B42v7 and CMORPH. Thus, the selected SPPs were used as input for the model uncertainly analysis, sensitivity, and calibration as well as validation individually through the same time.

3.3.1. Sensitivity Analysis. The sensitive parameters of the selected SPPs have been presented in Table 4. Initially, selectively sixteen parameters were used for the analysis; six for CMORPH and seven for TMPA3B42v7 had been selected as sensitive based on $T$-stat and $p$ value $(p<0.05)$. The 
parameters with larger $T$-stat and smaller $p$ value were considered as more sensitive for stream flow simulation.

Based on the analysis in Table 5, curve number $\left(\mathrm{CN}_{2}\right)$ was the first sensitive parameter for flow simulation for all cases. Other sensitive parameters were selected with a sensitive value ranging from 0.00 to 0.05 . The base flow recession constant (Alfa-Bf, days), groundwater delay (GWDELAY, days), soil available water capacity (SOILAWC, $\mathrm{mm} \mathrm{H}_{2} \mathrm{O} / \mathrm{mm}$ soil), plant uptake compensation factor (EPCO), and soil depth (SOL-Z, mm) for CMORPH product were taken into consideration, whereas the groundwater delay (GW-DELAY, days), the base flow recession constant (Alfa-Bf, days), soil available water capacity (SOIL-AWC, $\mathrm{H}_{2} \mathrm{O} / \mathrm{mm}$ ), plant uptake compensation factor (EPCO), soil depth (SOL-Z, mm), and maximum canopy index (CANMX) for TMPA3B42v7.

3.3.2. Calibration and Validation Value of SPPs. Monthly simulated and observed stream flow simulations reasonably agreed with the objective function for TMPA3B42v7 $E_{\mathrm{NS}}$ of 0.72 and $R^{2}$ of 0.81 and $E_{\mathrm{NS}}$ of 0.75 and $R^{2}$ of 0.69 for calibration and validation period, respectively (Figure 4). By using the similar time window, the calibration and validation of the observed stream flow with CMORPH below the objective function $E_{\mathrm{NS}}$ of 0.61 and $R^{2}$ of 0.75 and $E_{\mathrm{NS}}$ of 0.65 and $R^{2}$ of 0.64 , respectively (Figure 4 ). The mean monthly observed and simulated flow during calibration was estimated to be for TMPA3B42v7, $402.95 \mathrm{~m}^{3} / \mathrm{s}$ and $375.38 \mathrm{~m}^{3} / \mathrm{s}$ as well as for CMORPH, $420.2 \mathrm{~m}^{3} / \mathrm{s}$ and $348.8 \mathrm{~m}^{3} / \mathrm{s}$, respectively. Similarly, for validation, TMPA3B42v7 and CMORPH were $450 \mathrm{~m}^{3} / \mathrm{s}$ and $405.2 \mathrm{~m}^{3} / \mathrm{s}$, respectively, and $402.3 \mathrm{~m}^{3} / \mathrm{s}$ and $343.98 \mathrm{~m}^{3} / \mathrm{s}$, respectively. The PBIAS of TMPA3B42v7 product underestimated the observed stream flow by $23.1 \%$ while CMORPH by $39.8 \%$, whereas for validation the PBIAS underestimate the observed by $11.6 \%$ for TMPA3B42v7 overestimation the observed by $14.6 \%$ for CMORPH (Table 6 ).

3.3.3. Uncertainty Analysis. $58 \%$ and $50 \%$ of the observed data were bracketed by 95PPU during calibration when the TMPA3B42v7 and CMORPH products were used as model input and validation period for TMPA3B42v7 (69\%) and CMOPRH (51\%) products. Therefore, it can be assessed that there was a reduction in 95PPU (p-factor) for the period of validation which signposts uncertainties in the input driving variables. TMPA-3B42v7 product has low flow, and most of the peaks could follow the patterns of the observed hydrograph. Throughout the model and simulation, the results are finely tuned with the observed hydrographs in many aspects like peak flow, rising limb, and recession limb, but the peak flow for the year 2004-2006 is minutely underestimated compared to the observed hydrograph, and most of the observed peak values especially from May to September 2004-2006 were found to be above 95PPU band. The result was due to underestimation of SPPs leaping to the gauged rainfall data in the year. Similarly, during calibration of CMORPH products, the peaks of the simulated hydrograph were generally overestimated compared to the observed hydrograph excluding 2004 and 2006.

3.4. Comparison of SWAT Model Performance for SPPS. According to Table 6, the analysis of sensitive parameters was prepared separately. As a result, seven parameters were identified as significantly sensitive in common for TMPA3B42v7 and CMORPH SPPS. On the other hand, the absolute $T$-stat values and their sensitivity ranking were different in each case (Table 7 ).

The curve number (CN2) and ground water delay (GW_DELAY) resulted larger $T$-stat values in the case of TMPA3B42v7 rainfall input than CMORPH rainfall inputs, which indicates the change in these parameters had a greater impact on stream flow simulation when TMPA3B42v7 was used as model input than CMORPH satellite rainfall estimates. The base flow recession constant (Alfa-Bf, days) and soil available water capacity (SOIL_AWC) revealed larger $T$ stat value in the case of CMORPH rainfall input than TMPA3B42v7 rainfall inputs, which indicates that the change in these parameters had a greater impact on stream flow simulation when CMORPH was used than TMPA3B42v7. The manifestation of many peaks in the model efficiency in most of the parameters identified that assessment of these parameters might not be feasible for TMPA3B42v7-based simulations. Unlike to that of TMPA3B42v7, in the case of CMORPH-based simulation, the peaks of the model efficiencies were clearly presented for all selected parameters. Thus, it can be noted that the identify ability of the sensitive parameters has been increased from TMPA3B42v7 to CMORPH satellite rainfall-based simulations.

For the TMPA3B42v7 product for calibration and validation, the observed data were bracketed by 95PPU with $58 \%$ and $69 \%$, whereas for CMORPH product it was $50 \%$ and $51 \%$, respectively (Table 8 ). Consequently, it is clear that, in the calibration and validation stage, the model shows slightly larger prediction uncertainties when CMORPH SPPs was used as a model input with TMPA3B42v7 SPPs. These model uncertainties can be accounted for some errors in rainfall input sources, data preparation, and parameterization.

\subsubsection{Comparison Based on Model Performance Statistics.} The SWAT model calibration with TMPA3B42v7 satellite rainfall estimates revealed $R^{2}$ of 0.81 and $E_{\mathrm{NS}}$ of 0.72 and calibration of the model with CMORPH satellite rainfall estimates results with $R^{2}$ of 0.75 and $E_{\mathrm{NS}}$ of 0.61 respectively (Table 9). This clearly showed that SWAT model has a good performance when calibrated with TMPA3B42v7 satellite rainfall estimates than $\mathrm{CMORPH}$ satellite rainfall estimates according to the model efficiency evaluation criteria.

The average monthly stream flows simulated by the model during calibration period were $165.38 \mathrm{~m}^{3} / \mathrm{s}$ and $187.8 \mathrm{~m}^{3} / \mathrm{s}$ for TRMM3B42v7 and CMORPH SPPs, respectively. Compared to that of the observed mean monthly flow of the calibration time series $\left(133 \mathrm{~m}^{3} / \mathrm{s}\right)$, there was an underestimation of the observed stream flow with PBIAS for 
TABLE 5: Model parameters for calibrating SPPs.

\begin{tabular}{|c|c|c|c|c|c|c|}
\hline Name of para & $T$-stat & $p$ value & Rank & Parameter range & Fitted value & Sensitivity \\
\hline \multicolumn{7}{|c|}{ TMPA3B42v7 product } \\
\hline $\mathrm{CN} 2$ & 17.4 & 0.001 & 1 & {$[-0.2-0.2]$} & 0.11 & \multirow{7}{*}{ High } \\
\hline GW-DELAY & 3.84 & 0.001 & 3 & {$[30-450]$} & 47.7 & \\
\hline ALPHA-BF & 4.09 & 0.001 & 2 & {$[0-1]$} & 0.62 & \\
\hline SOL-AWC & 2 & 0.001 & 4 & {$[-0.25-0.25]$} & 0.13 & \\
\hline EPCO & 1.5 & 0.03 & 5 & [0-1] & 0.39 & \\
\hline SOL-Z & 0.84 & 0.045 & 6 & {$[-0.25-0.25]$} & 0.0285 & \\
\hline CANMAX & 0.78 & 0.05 & 7 & {$[0-10]$} & 6.19 & \\
\hline \multicolumn{7}{|c|}{ CMORPH product } \\
\hline CN2 & 13.09 & 0.001 & 1 & {$[-0.2-0.2]$} & 0.09 & \multirow{6}{*}{ High } \\
\hline ALPHA-BF & 2.24 & 0.001 & 3 & {$[0-1]$} & 0.62 & \\
\hline GW-DELAY & 2.01 & 0.001 & 4 & [30-450] & 37.7 & \\
\hline SOL-AWC & 3.5 & 0.001 & 2 & {$[-0.25-0.25]$} & 0.16 & \\
\hline EPCO & 1.13 & 0.02 & 5 & {$[0-1]$} & 0.34 & \\
\hline SOL-Z & 0.98 & 0.03 & 6 & {$[-0.25-0.25]$} & 0.049 & \\
\hline
\end{tabular}

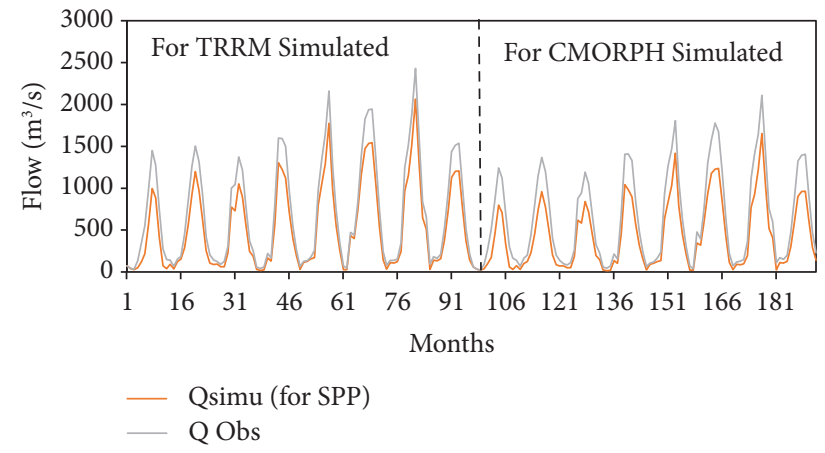

FIGURE 4: Monthly calibration results of observed: (a) TRMM3B42v7. (b) CMORPH simulated flow.

TABLE 6: Function of simulation and uncertainty measurements (2003-2018).

\begin{tabular}{lcccccc}
\hline & & \multicolumn{3}{c}{ Model performance indicators } & \multicolumn{2}{c}{ Uncertainty measures } \\
Simulation (months) & SPPs & $R^{2}$ & $E_{\mathrm{NS}}$ & PBIAS (\%) & $p$ factor & $r$-factor \\
\hline \multirow{2}{*}{ Calibration (2003-2010) } & TMPA3B42v7 & 0.81 & 0.72 & -21.3 & 0.58 & 0.85 \\
& CMORPH & 0.75 & 0.61 & -37.2 & 0.50 & 0.77 \\
\hline \multirow{2}{*}{ Validation (2011-2018) } & TMPA3B42v7 & 0.69 & 0.75 & -11.6 & 0.69 & 0.8 \\
& CMORPH & 0.64 & 0.66 & 14.6 & 0.51 \\
\hline
\end{tabular}

TABLe 7: Satellite rainfall estimate with $T$-stat value (most sensitive).

\begin{tabular}{lcccccc}
\hline $\begin{array}{l}\text { Parameter } \\
\text { name }\end{array}$ & \multicolumn{2}{c}{ In-situ } & \multicolumn{2}{c}{ TMPA3B42v7 } & \multicolumn{2}{c}{ CMORPH } \\
& T-stat & Ranking & T-stat & Ranking & $\begin{array}{c}T \text { - } \\
\text { stat }\end{array}$ & Ranking \\
\hline CN2 & 22.22 & 1 & 17.74 & 1 & 13.09 & 1 \\
ALPHA_BF & 3.49 & 5 & 2.24 & 3 & 4.09 & 2 \\
GW_DELAY & 8.37 & 2 & 3.84 & 2 & 2.01 & 4 \\
SOL_AWC & 5.71 & 4 & 2 & 4 & 3.5 & 3 \\
EPCO & 0.333 & 11 & 1.5 & 5 & 1.13 & 5 \\
CANMX & 1.23 & 8 & 0.78 & 7 & - & - \\
SOL_Z & 0.97 & 9 & 0.84 & 6 & 0.98 & 6 \\
\hline
\end{tabular}

TMAP 3B42v7 and CMORPH SPP was $21.3 \%$ and $37.2 \%$, respectively (Table 8 ). As a result, SWAT model stream flow simulation performance was better when calibrated with
TABLE 8: Summary of uncertainty measure statistics using SPPs.

\begin{tabular}{lcccc}
\hline & \multicolumn{2}{c}{$\begin{array}{c}\text { Calibration } \\
(2003-2010)\end{array}$} & \multicolumn{2}{c}{$\begin{array}{c}\text { Validation } \\
(2011-2018)\end{array}$} \\
Rainfall type & $p$-factor & $r$-factor & $p$-factor & $r$-factor \\
\hline TMPA3B42v7 & 0.58 & 0.85 & 0.69 & 0.8 \\
CMORPH & 0.50 & 0.77 & 0.51 & 0.57
\end{tabular}

TRMM3B42v7 SPP than CMORPH SPP in the study area. Similarly, the model validation with TMPA3B42v7 SPP was $R^{2}$ of 0.69 and $E_{\mathrm{NS}}$ of 0.75 , whereas, for CMORPH SPP model performance statistics result was $R^{2}$ of 0.64 and $E_{\mathrm{NS}}$ 0.66 . The average monthly stream flows simulated by the model during validation period were $88.93 \mathrm{~m}^{3} / \mathrm{s}$ and $65.8 \mathrm{~m}^{3} / \mathrm{s}$ for TMPA3B42v7 and CMORPH SPPs, respectively. Within the observed mean monthly flow of the 
validation, time series $\left(78.8 \mathrm{~m}^{3} / \mathrm{s}\right)$, underestimation of the observed stream flow with PBIAS of $11.6 \%$ and an overestimation of the observed discharge by $14.6 \%$ for TMPA3B42v7 and CMORPH, respectively, were recorded. Therefore, from the analysis, it can be concluded that SWAT model shows a better performance in stream flow simulation when TMPA3B42v7 product was used as a model input than $\mathrm{CMOPRPH}$ product in the study area.

3.5. Comparison of Gauged and SPPs. The main objective of the comparison was to evaluate the performance of SWAT model with in situ and SPPs, which was better in TMPA3B42v7.

\subsubsection{Comparison Based on Sensitivity and Uncertainty} Analysis. The absolute $T$-stat values and their sensitivity ranking were different, but the final fitted values of the common sensitive parameters were similar (Table 10).

The number (CN2), groundwater delay (GW-DELAY, days), and soil available water capacity (SOIL-AWC) resulted larger $T$-stat value in the case of in situ rainfall input than TRMM3B42v7 satellite rainfall inputs, which indicates the change in these parameters had a greater impact on stream flow simulation when in situ rainfall data was used as a model input than TRMM3B42v7 satellite rainfall. The percentage of observed stream flow was bracketed by the 95PPU band ( $p$ factor) for calibration $(81 \%)$ and for validation (68\%) for in situ rainfall data and it was 58\% and 69\% during the calibration and validation periods for TMPA3B42v7, respectively (Table 11).

The highest percentage of $p$ factor during the SWAT model uses in situ rainfall data as an input compared to TMPA3B42v7 satellite rainfall estimates indicating a considerable performance of the model obtained when in-situ rainfall data was used as a model input than satellite rainfall estimates.

\subsubsection{Comparison Based on Model Performance Statistics.} The SWAT model calibration results with in situ and TMPA3B42v7 satellite estimates were used for the model performance statistics. The mean monthly stream flow simulated by the model during calibration period was $168.3 \mathrm{~m}^{3} / \mathrm{s}$ for in situ and TMPA3B42v7 compared to the observed stream flow of $133 \mathrm{~m}^{3} / \mathrm{s}$. Consequently, both the in situ and TMPA3B42v7 rainfall products underestimation of the observed stream flow with PBIAS of $8.2 \%$ and $23.1 \%$ respectively were recorded. These results indicated that SWAT model has a very good performance when calibrated with in situ rainfall data than satellite rainfall estimates according to the model efficiency evaluation criteria as well as the capacity of simulating the stream flow (Table 12).

In situ rainfall products overestimate the observed discharge with PBIAS of $16.5 \%$ and TMPA3B42v7 rainfall products underestimate with $11.6 \%$. The results showed that SWAT model has still a good performance when validated with in situ rainfall products than satellite rainfall products due to the model efficiency evaluation criteria as well as the capacity of simulating the stream flow. SWAT model shows a good performance in stream flow simulation when in situ
TABLE 9: Summary of model performance results of SPPs.

\begin{tabular}{lcccccc}
\hline & \multicolumn{3}{c}{$\begin{array}{c}\text { Calibration } \\
(2003-2010)\end{array}$} & \multicolumn{3}{c}{ Validation } \\
& $R^{2}$ & $E_{\mathrm{NS}}$ & PBIAS & $R^{2}$ & $E_{\mathrm{NS}}$ & PBIAS \\
Rainfall type & $R^{2018)}$ \\
\hline TMPA3B42v7 & 0.81 & 0.72 & -21.3 & 0.69 & 0.75 & -11.6 \\
CMORPH & 0.75 & 0.61 & -37.2 & 0.64 & 0.66 & 14.6 \\
\hline
\end{tabular}

TABLE 10: Comparison of the sensitive parameters for in-situ and SPP.

\begin{tabular}{lcccc}
\hline \multirow{2}{*}{ Parameter name } & \multicolumn{2}{c}{ In situ } & \multicolumn{2}{c}{ TRMM3B42v7 } \\
& T-stat & Ranking & T-stat & Ranking \\
\hline CN2 & 22.22 & 1 & 17.74 & 1 \\
ALPHA_BF & 3.49 & 5 & 2.24 & 3 \\
GW_DELAY & 8.37 & 2 & 3.84 & 2 \\
SOL_AWC & 5.71 & 4 & 2 & 4 \\
EPCO & 0.333 & 11 & 1.5 & 5 \\
CANMX & 1.23 & 8 & 0.78 & 7 \\
SOL_Z & 0.97 & 9 & 0.84 & 6 \\
\hline
\end{tabular}

TABLE 11: Statistical analyses comparing the uncertainty measure of in situ and SRP.

\begin{tabular}{lcccc}
\hline & \multicolumn{2}{c}{$\begin{array}{c}\text { Calibration } \\
(2003-2010)\end{array}$} & \multicolumn{2}{c}{ Validation } \\
& \multicolumn{2}{c}{$(2011-2018)$} \\
Rainfall type & $p$-factor & $r$-factor & $p$-factor & $r$-factor \\
\hline In situ & 0.81 & 0.81 & 0.68 & 0.76 \\
TRMM-3B42v7 & 0.58 & 0.85 & 0.69 & 0.8 \\
\hline
\end{tabular}

TABLE 12: Statistical analyses comparing the model performance results with in-situ and SPP.

\begin{tabular}{lcccccc}
\hline & \multicolumn{3}{c}{ Calibration } & \multicolumn{2}{c}{ Validation (2010-2018) } \\
& \multicolumn{2}{c}{$(2003-2010)$} & & \\
Rainfall type & $R^{2}$ & $E_{\mathrm{NS}}$ & PBIAS (\%) & $R^{2}$ & $E_{\mathrm{NS}}$ & PBIAS (\%) \\
\hline In-situ & 0.9 & 0.89 & -8.2 & 0.76 & 0.64 & 16.5 \\
TMPA3B42v7 & 0.81 & 0.72 & -21.3 & 0.69 & 0.75 & -11.6 \\
\hline
\end{tabular}

rainfall data were used as model input than SPPs in the watershed. The underestimation of the stream flow simulated by SPPs and the reduction of model performance statistics were due to the underestimation of the input satellite rainfall estimates and the contamination of SPPs with systematic and random errors.

3.6. Impact of Bias Correction for Satellite Rainfall Estimates. Time and space variant bias correction algorithm was applied to minimize the systematic errors or biases of SPPs. Bias corrected SPPs were used again as a model input independently to evaluate how well the observed hydrographs can be reproduced (Table 13).

The results clearly indicate that the model performance statistics values have been augmented when the SWAT model uses the bias-corrected SPPs for both calibration and validation periods. The underestimation of the observed stream flow has been decreased when the model uses the bias correction of SPPs with PBIAS from $21.3 \%$ to $15.65 \%$ for TMPA3B42v7 and from $11.6 \%$ to $8.53 \%$ for CMORPH. 
TABle 13: Model performance statistics after bias-corrected SPPs.

\begin{tabular}{lcccc}
\hline \multirow{2}{*}{ Performance statistic } & \multicolumn{2}{c}{ Calibration period (2003-2010) } & \multicolumn{2}{c}{ Validation period (2011-2018) } \\
& Bias-corrected TMPA3B42v7 & Bias-corrected CMORPH & Bias-corrected TMPA3B42v7 & Bias-corrected CMORPH \\
\hline$R^{2}$ & 0.88 & 0.81 & 0.72 & 0.69 \\
$\mathrm{E}_{\mathrm{NS}}$ & 0.78 & 0.73 & 0.78 & 0.72 \\
PBIAS & -15.65 & -22.1 & -8.53 & 12.32 \\
$p$ factor & 0.73 & 0.7 & 0.7 & 0.69 \\
$r$-factor & 0.45 & 0.51 & 0.53 & 0.47 \\
\hline
\end{tabular}

Overestimation of the observed stream flow has been decreased from $14.6 \%$ to $12.32 \%$ for CMORPH products. The observed data were bracketed by the 95PPU band ( $\mathrm{p}$-factor) throughout the calibration as well as validation periods depicting that model prediction uncertainty had been decreased (higher p-factor value has been obtained) when biascorrected SPPs were applied. Therefore, bias-corrected SREs had better performance than uncorrected SREs for stream flow simulation, but their performance was relatively poor than in situ rainfall data [27].

\section{Conclusions}

The SWAT model was used and evaluated for stream flow simulation in Abelti watershed of the Upper Omo-Gibe Basin, Ethiopia. The hydrometeorological data were obtained from gauging stations and SREs for the period from 2000 to 2018. This research mainly focuses on a comprehensive combined using of the gauged and SREs for better accuracy of the results. CMORPH, TMPA3B42v7, and in situ products were used independently for simulating the watershed area. Bias-corrected SPPs were also considered in the simulation to check their impact on the model performance efficiency. Based on the analysis of sensitivity through gauged and SPPs data, the seven most sensitive parameters were selected by considering the $T$-stat and $p$ value. As a result, the curve number $(\mathrm{CN} 2)$ was the first sensitive parameter for all rainfall products, whereas CANMAX was the least sensitive parameter in the watershed. The calibration and validation were done using a monthly time step which provided superior result for all stages. The TMPA3B42v7 rainfall product performed better than CMORPH product during the calibration and validation periods. The low SWAT model performance has been observed when it was calibrated and validated using CMORPH product than TMPA3B42v7 product. This is due to rugged and high elevated topography of the study area. TMPA3B42v7 SRE has good capability in capturing precipitation values in higher elevation areas than CMORPH SRE, which is slightly affected by the elevation difference. CMORPH and TMPA3B42v7 satellite rainfall data showed overestimation and underestimation of the simulated stream flow due to random and systematic errors, although its simulation results captured the shape of the observed stream flow hydrograph. When the model is calibrated and validated with bias-corrected satellite precipitation estimates, its performance significantly increases. However, the model performance of stream flow simulation using these bias-corrected satellite precipitation estimates was still lower than the simulation results of in situ precipitation products.

\section{Data Availability}

Most of the secondary data used in this research were collected from Ministry of Water, Irrigation and Electricity, Ethiopia (MWIEE) and National Meteorological Agency, Ethiopia (NMAE).

\section{Conflicts of Interest}

The authors declare that there are no conflicts of interest related to the publication of this paper.

\section{Acknowledgments}

The authors acknowledge Ministry of Water, Irrigation and Energy of Ethiopia for their necessary data and information provision in this study. The authors would also like to express their sincere appreciation to National Meteorological Agency for their support by providing gauging rainfall data and Arba Minch University for providing all sorts of logistic support to conduct this research.

\section{References}

[1] Z. Zhang, J. Tian, Y. Huang, X. Chen, S. Chen, and Z. Duan, "Hydrologic evaluation of TRMM and GPM IMERG satellitebased precipitation in a humid basin of China," Remote Sensing, vol. 11, no. 4, p. 431, 2019.

[2] L. Haileyesus, M. Semu, and A. Dereje, "Hydrological evaluation of satellite and reanalysis precipitation products in the upper blue nile basin: a case study of Gilgel Abbay," $\mathrm{Hy}$ drology, vol. 4, p. 39, 2017.

[3] C. Toté, D. Patricio, H. Boogaard, R. van der Wijngaart, E. Tarnavsky, and C. Funk, "Evaluation of satellite rainfall estimates for drought and flood monitoring in Mozambique," Remote Sensing, vol. 7, no. 2, pp. 1758-1776, 2015.

[4] Y. Wang, Y. Wang, and $\mathrm{H}$. Xu, "Impacts of $1.5^{\circ} \mathrm{C}$ and $2.0^{\circ} \mathrm{C}$ global warming on runoff of three inland rivers in the hexi corridor, northwest China," Journal of Meteorological Research, vol. 34, no. 5, pp. 1082-1095, 2020.

[5] A. Behrangi, B. Khakbaz, T. C. Jaw, A. AghaKouchak, K. Hsu, and S. Sorooshian, "Hydrologic evaluation of satellite precipitation products over a mid-size basin," Journal of $\mathrm{Hy}$ drology, vol. 397, no. 3-4, pp. 225-237, 2011.

[6] L. Carlos, K. Y. Amoako, and A. Adebayo, United Nations Economic Commission for Africa, Climate Change and Water in Africa: Analysis of Knowledge Gaps and Needs, United Nations Economic Commission for Africa, African Climate Policy Centre, ACPC Working Paper, Addis Ababa, Ethiopia, 2011, https://hdl.handle.net/10855/21125.

[7] D. P. Lettenmaier, D. Alsdor, J. Dozier, G. J. Huffman, and M. Pan, "Wood in Roads of remote sensing into hydrologic 
science during the WRR era," Journal of Water Research, vol. 10, no. 1002, pp. 7309-7342, 2015.

[8] H. E. Beck, A. I. J. M. van Dijk, V. Levizzani et al., "MSWEP: 3hourly $0.25^{\circ}$ global gridded precipitation (1979-2015) by merging gauge, satellite, and reanalysis data," Hydrology and Earth System Sciences, vol. 21, no. 1, pp. 589-615, 2017.

[9] Y. Derin, E. Anagnostou, A. Berne et al., "Evaluation of GPMera global satellite precipitation products over multiple complex terrain regions," Remote Sensing, vol. 11, no. 24, p. 2936, 2019.

[10] M. A. Ehsan Bhuiyan, E. I. Nikolopoulos, and E. N. Anagnostou, "Machine learning-based blending of satellite and reanalysis precipitation datasets: a multiregional tropical complex terrain evaluation," Journal of Hydrometeorology, vol. 20, no. 11, pp. 2147-2161, 2019.

[11] A. Belayneh, G. Sintayehu, K. Gedam, and T. Muluken, "Evaluation of satellite precipitation products using HECHMS model," Modeling Earth Systems and Environment, vol. 6 , no. 4, pp. 2015-2032, 2020.

[12] L. Haileyesus, M. Semu, and A. Dereje, "Hydrological performance evaluation of multiple satellite products in upper Blue nile basin, Ethiopia," Journal of Hydrology, vol. 27, 2020.

[13] E. Habib, A. Haile, N. Sazib, Y. Zhang, and T. Rientjes, "Effect of bias correction of satellite-rainfall estimates on runoff simulations at the source of the upper blue nile," Remote Sensing, vol. 6, no. 7, pp. 6688-6708, 2014.

[14] Y. Ashenafi and D. Hailu, "Assessment of the use of satellite rainfall product for runoff simulation in the upper Blue Nile Basin, Ethiopia," Journal of EEA, vol. 31, 2014.

[15] H. Alemseged, E. Habib, M. Elsaadani, and T. Rientjes, "Inter comaprison of satellite rainfall products for represnting raifall diurnal cycle over the Nile Basin," Internal Journal of Applied Earth observationand Geoinformation, vol. 21, pp. 230-240, 2013.

[16] M. Bitew and G. Mekonnen, "Evaluation of percipitation products throughsteramflow hydrologic simulation in fully distributed hydrologic model," Journal of Water Resources Research, vol. 47, no. 6, 2011.

[17] M. M. Bitew and M. Gebremichael, "Assessment of satellite rainfall products for streamflow simulation in medium watersheds of the Ethiopian highlands," Hydrology and Earth System Sciences, vol. 15, no. 4, pp. 1147-1155, 2011.

[18] R. J. Joyce, J. E. Janowiak, P. A. Arkin, and P. Xie, "CMORPH: a method that produces global precipitation estimates from passive microwave and infrared data at high spatial and temporal resolution," Journal of Hydrometeorology, vol. 5, no. 3, pp. 487-503, 2004.

[19] G. J. Huffman, D. T. Bolvin, E. J. Nelkin et al., "The TRMM multisatellite precipitation analysis (TMPA): quasi-global, multiyear, combined-sensor precipitation estimates at fine scales," Journal of Hydrometeorology, vol. 8, no. 1, pp. 38-55, 2007.

[20] J. G. Arnold and N. Fohrer, "SWAT2000: current capabilities and research opportunities in applied watershed modelling," Hydrological Processes, vol. 19, no. 3, pp. 563-572, 2005.

[21] J. G. Arnold, D. N. Moriasi, P. W. Gassman et al., "SWAT model use, calibration and validation," American Society of Agricultural and Biological Engineers, vol. 55, no. 4, pp. 1491-1508, 2012.

[22] D. N. Moriasi, J. G. Arnold, M. W. Van Liew, R. L. Bingner, R. D. Harmel, and T. L. Veith, "Model evaluation guidelines for systematic quantification of accuracy in watershed simulations," American Society of Agricultural and Biological Engineers, vol. 50, no. 3, pp. 885-900, 2007.
[23] H. Gupta, S. Sorooshian, and P. O. Yapo, "Status of automatic calibartion for hydrologic models: comparison with multilevel expert calibration," Journal of Hydrologic Engineering, vol. 4, no. 2, pp. 135-143, 1999.

[24] F. A. Hirpa, M. Gebremichael, and T. Hopson, "Evaluation of high resolution satellite precipitation products over very complex terrian in Ethiopia," Journal of Applied Meteorologyand Climotology, vol. 49, no. 5, pp. 1044-1051, 2010.

[25] K. C. Abbaspour, User Manual of SWAT CUP, SWAT Calibration \& Unceratainity Analysis Programs, Swiss Federal Institute of Aquatic Science and Technology, Duebendorf, Switzerland, 2015.

[26] J. Yang, P. Reichert, K. C. Abbaspour, and H. Yang, "Hydrological modeling of CHaohe Basin in China: statistical model formulation," Journal of Hydrology, vol. 340, no. 3 - 4, pp. 167-182, 2007.

[27] B. Yong, H. Yang, L.-L. Ren et al., “Assessment of evolving TMM based multi-satellite real time precipitation estimation methods and thier impacts on hydrological modeling in high latitude basin," Jouurnal of Geophysical Research: Atmospheres, vol. 117, no. D9, 2012. 